\title{
Monitorar, negociar e confrontar As (re)definições na gestão dos ilegalismos em favelas "pacificadas"
}

Palloma Valle Menezes*

Introdução

Quando Sergio Cabral Filho assumiu o cargo de governador do Estado do Rio de Janeiro, em 2007, e nomeou José Mariano Beltrame como Secretario de Segurança, a "violência urbana" era considerada senão o principal, decerto um dos principais problemas e desafios a serem enfrentados no Estado e, principalmente, na cidade do Rio de Janeiro. Aquele era um momento de crescimento econômico no país. Os governos federal, estadual e municipal, depois de décadas de disputas intensas, estavam trabalhando juntos para que a "cidade maravilhosa" se tornasse sede da Copa do Mundo de 2014 e dos Jogos Olímpicos de 2016. Apesar disso, os índices de criminalidade e, em especial, de homicídios eram, na cidade, tidos como um dos pontos críticos que precisavam ser melhorados para que se garantisse a recepção dos grandes eventos e de investimentos internacionais. Foi nesse contexto mais amplo que, em novembro de 2008, começou a ser testado, então, um novo projeto de "policiamento comunitário"1. Projeto que, pouco tempo depois, receberia o nome Unidade de Polícia Pacificadora (UpP).

*Universidade Federal Fluminense, Niterói, Rio de Janeiro, Brasil.

1. Inicialmente, o termo utilizado para descrever o tipo de policiamento implementado pelas UpPs era "policiamento comunitário" e, posteriormente, passou a ser "policiamento de proximidade". Como não há uma definição precisa do que é o "policiamento de proximidade”, os próprios policiais que atuam nas UPPs têm dificuldades para estabelecer uma diferenciação precisa entre as duas nomenclaturas. 
Com base em uma pesquisa etnográfica ${ }^{2}$ realizada nas duas primeiras favelas do Rio de Janeiro onde foram inauguradas as Upps - o Santa Marta (localizado na Zona Sul da cidade) e a Cidade de Deus (localizada na Zona Oeste) - analiso, neste trabalho, as mudanças que a maior proximidade territorial entre os policiais e os jovens que atuam no comércio varejista de drogas ilegais gerou nas modalidades de presença e nos modos de ação (e interação) desses atores situados nas dobras do legal-ilegal (Telles, $2010)^{3}$. O objetivo central do presente artigo é, valendo-se da análise de contextos situados, refletir sobre as definições e redefinições que ocorreram na gestão diferencial dos ilegalismos (Foucault, 1987) em favelas a partir da inauguração das UPPs.

Na primeira sessão deste trabalho mostro como, inicialmente, a chegada da polícia no Santa Marta e na Cidade de Deus gerou uma situação indeterminada que levou moradores, policiais e traficantes a darem início ao que o filósofo pragmatista John Dewey (1938) chamou de "processo de investigação". Na segunda parte do texto, apresento as transformações no modo de atuação e funcionamento do comércio varejista de drogas nas duas primeiras regiões "pacificadas". Na terceira sessão, exponho como as próprias habilidades, capacidades e competências até então exigidas aos jovens que atuavam no tráfico de drogas também foram temporariamente alteradas e, com isso, uma nova normatividade imanente do bom traficante surgiu nos primeiros anos da "pacificação". Na quarta parte, mostro como, com o passar do tempo, houve uma rotinização das UPPs, além de um refortalecimento do tráfico de drogas. Com base neste último aspecto, apresento como as lógicas de negociação de "arregos" foram reformuladas. Na quinta sessão, trato da crise do projeto de "pacificação", chamando a atenção para a (re)intensificação das disputas territoriais ${ }^{4} \mathrm{em}$ áreas com UPP. E, por fim, sintetizo as principais dinâmicas associadas à gestão dos ilegalismos em favelas "pacificadas".

2. Essa pesquisa foi realizada inicialmente entre 2009 e 2014 . Nesse período, além de fazer observação participante, realizei entrevistas com moradores, policiais das UPPs e jovens envolvidos no "mundo do crime". Posteriormente, no final de 2015, voltei a campo para realizar novas entrevistas com PMS e moradores visando analisar o contexto de "crise das upps".

3. Como lembra Telles, a noção de ilegalismos cunhada por Michel Foucault (1987) é interessante porque "desloca a discussão da tautológica e estéril binaridade legal-ilegal, para colocar no centro da investigação os modos como as leis operam, não para coibir ou suprimir os ilegalismos, porém para diferenciá-los internamente. [...] Os ilegalismos [...] não são imperfeições ou lacunas na aplicação das leis, contêm uma positividade que faz parte do funcionamento do social, eles compõem os jogos de poder e se distribuem conforme se diferenciam os espaços protegidos e aproveitáveis em que a lei pode ser violada, outros em que pode ser ignorada, outros, enfim, em que as infrações são sancionadas. [...] É justamente nesses torneios da lei que as questões se configuram" (Telles, 2010, p. 26).

4. Este trabalho tem como ponto de partida a ideia de que a gestão diferencial dos ilegalismos e dos modos de gestão da violência na cidade do Rio de Janeiro, nas últimas décadas, encontra-se diretamente relacionada com as disputas do domínio territorial das favelas (Misse, 2007). Por isso, não é possível entender a gestão dos ilegalismos sem explorar as disputas territoriais que ocorrem nos morros cariocas. 
Defendo a hipótese de que monitorar, negociar e confrontar são as principais modalidades dos ilegalismos em favelas cariocas. Sugiro que analisar as variações e combinações entre essas modalidades - levando em consideração as assimetrias de poder entre os atores envolvidos -, ao longo do tempo, é fundamental para entender como os campos de forças presentes em favelas "pacificadas" foram se (re)desenhando ao longo dos últimos anos. Espero, com isso, oferecer pistas para a compreensão do processo de ascensão e queda das upps 5 .

\section{Só mais uma operação policial "normal"?}

Quando a upp chegou, eu me lembro! Foi a maior correria! Nós não sabíamos, não estávamos programados. Estávamos dormindo em casa com fuzil. [...] Nós estávamos acostumados com a favela tranquila. Sempre amanhecia arregadona. Então, nós chegávamos, deitava na cama, deixava o fuzil de um lado, pistola do outro, e ia dormir. Acordava, tomava banho, escovava o dente, botava o fuzil do lado, ligava a moto e saía para começar a colocar a boca para funcionar. Quando eu fui fazer isso, vi o Caveirão e falei: “ih, caralho"! Já desliguei a moto, fui pelo cantinho da parede, entrei em casa de novo e já acordei meus parceiros e falei: "qual foi, mano? Os canas estão aqui na favela”. [...] Papo vai, papo vem, liga para um, liga para outro [...] e para tirar os negócios [armas e drogas] de dentro da casa? Maior adrenalina doida, acordamos todo mundo. Moravam quatro moleques comigo: "vambora, vambora. Liga para fulana de tal, cicrana, mulher, prima, o que der para elas irem levando aos poucos". Então, foi assim: a polícia entrou, vários amigos dormindo, os canas invadiram, viram o fuzil do lado e nem esperou falar nada [...]. No dia que a UPP chegou morreram uns 9 [...]. A gente achava que era uma operação policial normal (Trecho de entrevista com um traficante da Cidade de Deus).

Quando a Polícia Militar do Estado do Rio de Janeiro ocupou a Cidade de Deus e o Santa Marta, em novembro de 2008, moradores e jovens que atuavam no comércio varejista de drogas ilegais nessas favelas pensaram estar diante de uma operação policial "normal”. A princípio, a ação policial parecia seguir o mesmo roteiro das incursões que há algumas décadas vinham ocorrendo nas favelas cariocas. Como descreveu um policial da UPP do Santa Marta:

5. É importante ressaltar que este artigo está centrado no plano dos cotidianos, no que chamo de fenomenologia do habitar da favela. Isso quer dizer que analiso os impactos da inauguração das upps na gestão dos ilegalismos em favelas com base nos ciclos de indeterminação-investigação-estabilização-novas indeterminações (para empregar a terminologia de John Dewey) que foram vivenciados pelos atores que habitam e/ou trabalham em favelas "pacificadas". Em um outro artigo, intitulado "From disarmament to rearmament: elements for a sociology of critique of Pacifying Police Unit", analiso o processo de ascensão e queda do projeto como parte de um ciclo maior de indeterminação-investigação-estabilização-novas indeterminações das próprias UPPs. 
Eu estava acostumado a trabalhar de que forma antes? Estou eu lá no Batalhão e recebo uma denúncia: "Ó, a denúncia... temos que prender o tal traficante que recebeu um carregamento de armas e está em tal lugar." Então, subia todo mundo armado de colete, fuzil, dez policiais, viatura entrava na comunidade, com certeza [tinha] troca de tiros, colocando a vida em risco dos marginais, dos moradores, e a minha vida e a dos policiais que estavam comigo. E era uma constante, porque toda vez que tinha uma denúncia, a gente reunia a equipe, vinha e trocava tiro, vinha e trocava tiro, resolvia o que tinha para resolver, saía da comunidade, o tráfico volta a dominar. No outro dia, a mesma coisa! [...] Quando mandaram a gente subir e ficar na favela, a gente não sabia muito bem o que aconteceria. A gente não achava que fosse ficar por muito tempo no morro, mas fomos ficando. Por ser a primeira unidade, nem polícia, nem comunidade sabiam como seria a UpP (Trecho de entrevista com um policial da UPP do Santa Marta).

Essa fala do policial evidencia que, como de costume, policiais fortemente armados entraram nas favelas contando com o fator surpresa, trocaram tiros com traficantes - gerando mortes, no caso da Cidade de Deus -, efetuaram prisões em flagrante e apreenderam drogas e armas. Apenas o último elemento do roteiro "padrão" das operações policiais de praxe nas favelas não fez parte da ação realizada em novembro de 2008: dessa vez, a polícia não se retirou dos territórios alguns dias após o início da incursão. Ela neles permaneceu.

Em um primeiro momento, ninguém entendeu muito bem o sentido da polícia continuar na favela. Os repertórios habituais de que dispunham os moradores dessas localidades não auxiliavam nesse trabalho interpretativo a respeito do que estava se passando. Não havia, inclusive, informações oficiais disponíveis sobre o que estava ocorrendo ou sobre o que iria ocorrer. Inicialmente, não houve qualquer anúncio formal ou informal de que seriam inauguradas no Santa Marta e na Cidade de Deus as duas primeiras Upps da cidade do Rio de Janeiro - até porque, naquele momento, o nome UPP ainda nem sequer existia.

Portanto, ninguém, nem mesmo o governo do Estado, tinha clareza e podia antecipar que naquele momento começava a ser elaborado e testado um projeto que ganharia enorme centralidade no debate sobre segurança pública no país. Menos ainda alguém podia supor que aquela experiência, posteriormente, seria classificada como uma das mais significativas em termos de segurança pública produzidas no Rio de Janeiro e mesmo no Brasil nas últimas décadas ${ }^{6}$.

6. Nos primeiros anos após a inauguração das UPPs formou-se um consenso em torno da ideia de que "após mais de três décadas de experimentos fracassados de programas de segurança pública no Rio de Janeiro”, o projeto apresentava-se como "uma resposta bem-sucedida para a questão da violência nesse estado, em especial na sua capital” (Burgos et al., 2012, p. 2). Por isso, projetos semelhantes à Upp foram implantados em outros estados brasileiros, como as Bases Comunitárias de Segurança (BCS) inauguradas em 2011 na Bahia. 
Como sintetizou Zé Mário, o presidente da Associação de Moradores do Santa Marta, no momento que o morro foi ocupado, a sensação dele próprio e de grande parte da população da favela era a de estar "entrando num grande túnel escuro, esperando chegar rapidamente do outro lado para ver muita luz". É possível dizer, portanto, que os habitantes do morro viveram aquele momento como uma "crise" (Shibutani,1966) ou "momento crítico" (Boltanski, 1990; Boltanski e Thévenot, 1991). Dito de outro modo, o início das UPps foi vivenciado pela população desses territórios como uma radical desrotinização momentânea da vida cotidiana, isto é, um evento que produziu uma ruptura com as formas habituais de ação, quebrando com as expectativas que os atores possuíam acerca de sua maneira rotineira de ser, de se comportar, de agir e de pensar.

A partir do contato com tal situação indeterminada, os habitantes da favela começaram a realizar um "processo de investigação" (Dewey, 1938), com a finalidade de compreender e tornar inteligível o que estava acontecendo. Tal investigação produziu-se como um processo reflexivo e experimental de reengajamento no "novo" ambiente da favela.

Zé Mário conta que, no caso do Santa Marta, essa investigação teve início quando muitas pessoas o procuraram para perguntar a respeito do que estava se passando na favela. Incapaz de dar uma resposta adequada, ele, por sua vez, procurou representantes do poder público, buscando elementos que permitissem ter um entendimento e uma definição da nova situação.

De forma semelhante, os jovens envolvidos com o comércio varejista de drogas nessas duas favelas também passaram pelo mesmo processo. Eles narram que, naquele momento crítico, acionaram os contatos de que já dispunham para operações policiais que ocorriam com relativa frequência, mas que quando notaram não mais estar diante de uma "operação policial normal", ficaram sem saber ao certo como agir:

Sabe como é que é, polícia é bandido, bandido é polícia, é assim. Como eles têm nossa informação daqui para lá, nós temos de lá para cá também. Aí nós batemos um rádio para a arregadeira [policiais corruptos], mandamos ir no comandante para ver se ia ter papo. Aí o comandante falou: "você está maluco? Agora não tem mais nada, não tem negociação. A polícia vai ficar. Pode falar para eles!" De tarde, foi uma loucura, atravessando daqui para a Penha de moto roubada, casacão, fuzil, pistola pra caralho voando na Linha Amarela. O dono da boca na tua garupa, foragido pra caralho. Não foi eu que levei ele não, fui em outra moto, mas estava todo mundo num bonde só. Aí você fica como? Tinha que, ao mesmo tempo, ficar na contenção do cara e pilotar a moto! Tu vai deixar o dono da boca para morrer contigo ali? Tu morre, mas não pode deixar o cara morrer. Aí fomos, deixamos ele lá. Depois voltou, ficou assim [...] Aí perto do Natal entrou a Upp (Trecho de entrevista com um traficante da Cidade de Deus). 
O depoimento torna evidente que, naquele momento, era essencial para os jovens envolvidos no "mundo do crime" (Grillo, 2013) buscar informações para que pudessem traçar estratégias minimamente seguras de ação. No entanto, a única informação que tiveram era de que, a partir daquele momento, a polícia ficaria na favela por tempo indeterminado. Foi, portanto, preciso aos traficantes improvisarem uma nova estratégia de ação.

Como boa parte do que era tomado como óbvio (taken for granted) pelos traficantes tinha deixado de sê-lo de maneira brusca e repentina, eles precisaram iniciar uma busca por uma nova "ação que convém” (Thévenot, 1990). Então, ainda que de modo precário e permeado de riscos, alguns resolveram se esconder dentro da própria favela. Apenas poucos traficantes de áreas específicas, como o Karatê na Cidade de Deus, resolveram enfrentar diretamente a polícia em meio à situação indeterminada. Parte significativa dos traficantes (sobretudo os de alta hierarquia) fugiram temporariamente e se abrigaram em outras favelas não ocupadas pela polícia e, portanto, mais seguras para eles naquele momento.

\section{O comércio varejista de drogas "pacificado"}

Uma das principais consequências desse momento inicial de indeterminação gerado pela chegada da polícia na favela foi um enfraquecimento temporário do tráfico de drogas ilícitas nas áreas ocupadas. No caso do Santa Marta, poucas semanas após o início da ocupação do morro, foram divulgadas diversas reportagens em jornais cariocas que apontavam não haver mais venda de drogas na favela.

No caso da Cidade de Deus, moradores contam que, no início da ocupação policial, em 2008, o tráfico perdeu muita força porque um grande número de traficantes fugiu da favela e alguns poucos ficaram bem escondidos e passaram a efetuar pouco ou quase nenhuma venda, por temerem os policiais do Batalhão de Operações Policiais Especiais (Bope). Diversos relatos apontaram que no início da ocupação policial: "a igreja ficou lotada de bandido. [...] O negócio ficou salgado. O Bope vinha aí, batia de porta em porta. O Bope só trabalhava de madrugada. $\mathrm{Na}$ madruga era corda no pescoço, gravata, cabo de vassoura e pau neles. Todo mundo ficou aterrorizado".

Assim que o Bope deixou a favela e foi inaugurada a UPP, os moradores da Cidade de Deus tiveram que se adaptar à nova situação. Aqueles que tinham fugido para outras favelas e voltaram para "casa”, logo notaram que trabalhar no tráfico em uma favela "pacificada” não seria a mesma coisa que antes. Houve também uma drástica redução dos rendimentos e do espaço objetivo de cargos dentro da boca de fumo local. Por isso, vários jovens resolveram procurar um emprego formal. 
Aqueles que decidiram continuar atuando no comércio de drogas ilícitas, tanto na Cidade de Deus como no Santa Marta, entenderam em um primeiro momento que não era plausível retomar por completo o domínio territorial da favela, dada permanência e a superioridade do poder armado do Estado naquele momento. Como também não era possível naquele primeiro momento do projeto das up ps estabelecer algum tipo de negociação envolvendo "arrego", os traficantes perceberam que para subsistir nos territórios teriam que alterar suas condições de existência. Passaram, então, a testar novas estratégias de ação e adaptar o comércio de drogas para que ele sobrevivesse no novo ambiente.

Segundo meus interlocutores, as principais mudanças no comércio varejista de drogas ilícitas em favelas logo após a chegada da upp foram: (a) a venda se tornou menos "sedentária" (Grillo, 2013) (ou seja, os pontos de venda passaram a variar mais de lugar); (b) os vendedores passaram a trabalhar de forma mais dissimulada e menos ostensiva (já que deixaram de ostentar armas com frequência); (c) grande parte das vendas passou a acontecer através do modo chamado de "estica" (os traficantes deixaram de carregar a droga nos bolsos ou em mochilas e passaram a deixar pequenas "cargas" escondidas em algum lugar próximo de onde estavam); (d) houve um aumento da utilização de menores de idade como vendedores de droga; (e) também ocorreu um aumento no número de pessoas trabalhando como "olheiros". Um traficante da Cidade de Deus expôs essas mudanças da seguinte forma:

\begin{abstract}
Antigamente, tinha ponto fixo, até porque a dificuldade dos policiais chegarem na boca do tráfico era maior [...] Depois das três da tarde, era bem mais difícil eles chegarem. Hoje em dia é fácil, então eles já estão aqui. Se a UPP já passou, já botou os moleques para correr aqui, voltar para o mesmo lugar é maluquice, porque eles já vão para outro lugar. Antigamente, o cara ficava de bolsa na mão, hoje em dia a droga está entocada lá na beira do rio, lá embaixo, e ele [o traficante] está aqui, ele pega o dinheiro e vai lá de bicicleta. Antigamente, os caras guardavam muita coisa junta em um lugar só, agora está tudo bem mais espalhado. Antigamente, todo mundo queria andar armado, hoje não, você andar armado, de pistola, é bobeira, porque não tem necessidade de andar. Você vai perder uma peça do cara de bobeira, vai perder para um policial que vai te pegar com certeza. Um dia desses aí, três menores deram bobeira indo para baile de arma. Uma pistola sumiu porque o moleque foi para o baile com ela [...] A minha está guardada lá, eu vou usar para quê? Para mim, vai ficar lá (Trecho de entrevista com um traficante da Cidade de Deus).
\end{abstract}

O comandante da upp da Cidade de Deus descreveu essa mudança como uma "adaptação dos traficantes ao novo ambiente". Em uma entrevista, ele destacou que a presença de menores no tráfico se intensificou de forma considerável, passando a 
dificultar muito o trabalho da polícia na favela. Um traficante da Cidade de Deus apontou durante uma conversa que o uso dessa mão de obra era necessário naquele momento, pois “os meninos que já tiveram passagem pela polícia ficam pichados. Os policiais conhecem até pela tatuagem. Tatuagem esverdeada de cadeia, aí os caras já olham. 'Opa, vem cá”. Por isso, na visão do próprio traficante, nesse contexto de "pacificação", "o que funciona mais é menor vender, porque se pegarem o menor não vai dar em nada mesmo. Vai e volta, vai hoje e volta depois de amanhã”.

O mesmo traficante destacou também que, depois da "pacificação", foi necessário aumentar o número de olheiros ou "atividades" atuando na favela. Como as "fronteiras tácitas" entre as áreas de atuação do tráfico e da polícia tornaram-se mais borradas e fluidas após a chegada da UPP (Grillo, mimeo.), os métodos utilizados para proteger aqueles que realizavam a venda de drogas - assim como as "cargas" e o material bélico existente na favela - também tiveram que mudar. Enquanto antes da UPP os dispositivos de vigilância concentravam-se principalmente na região fronteiriça entre o asfalto e o morro, de modo que os traficantes pudessem monitorar qualquer aproximação de policiais ou facções rivais em relação ao território, após a “pacificação" eles passaram a voltar-se sobretudo para o interior da favela.

Se antes a dinâmica da própria vigilância do tráfico em favelas era marcada por expectativas que deslizavam entre oposições rígidas - a ausência e ou a presença da polícia na favela -, no período pós "pacificação", ela se refinou e passou a estar relacionada com "gradações de presença” potencial da polícia no território. As fronteiras deixaram de ser extensas e bem demarcadas e tornaram-se intensivas e variáveis (DeLanda, 2010). Isso porque, a partir de 2009, novos instrumentos e estratégias de monitoramento das mobilidades passaram a ser utilizadas para que os traficantes pudessem investigar e mapear constantemente o fluxo de circulação tanto de pessoas, quanto de objetos e de informações pelo território. Tal mapeamento tornou-se essencial para que eles pudessem tentar mensurar da forma mais precisa possível as intensidades da presença de policiais da UPP nas mais variadas partes dos territórios "pacificados" - a recíproca sendo verdadeira.

7. Grillo (mimeo.) indica que “a divisão entre até onde se espera que traficantes vendam drogas e andem armados e até onde há policiamento regular tende a asseverar o contraste entre favela e asfalto. Já a demarcação dos territórios de atuação de uma ou outra facção impõe risco de vida a quem quer que ouse cruzar as fronteiras e frequentar favelas controladas por facções rivais, mesmo que se trate de moradores sem qualquer relação com o tráfico. Há ainda os limites geográficos impostos por traficantes à atuação de assaltantes". A autora aponta que a inauguração das UPPs gerou rearranjos nas relações de poder e ocasionaram deslocamentos nas fronteiras tácitas. A contiguidade entre policiais e traficantes dentro do espaço das favelas modificou a geopolítica local. 


\section{0 "bom traficante"}

Em resumo, é possível dizer que com “processo de investigação” que teve início após a chegada da UPP, uma nova "educação da atenção" (Gibson, 1979; Ingold, 2000) foi requisitada, isto é, uma nova modalidade de afinação do sistema perceptivo dos jovens envolvidos com o "mundo do crime" e com o ambiente foi necessária para "navegar" (Vigh, 2009) na ecologia sensível da favela pós-“pacificação”. Nesse sentido, o mapeamento do território das favelas "pacificadas” tornou-se essencial para que os traficantes - assim como os policiais da UPP - pudessem traçar estratégias de ação ajustadas ao novo ambiente.

Nesse processo de mapeamento do novo ambiente da favela, nos primeiros anos depois da inauguração da UPP, a força "sedentarizante" do fuzil passou a dar lugar à observação atenta dos olheiros e à comunicação "flexibilizante" dos celulares e radinhos usados para monitorar os fluxos de circulação de pessoas, objetos e informações que ocorriam nos territórios com upps. Desse modo, os dispositivos de monitoramento que antes eram usados mais na vigilância das fronteiras entre o morro e o "asfalto", passaram a ser utilizados em todo o território da favela e ganharam uma maior centralidade na atuação cotidiana dos traficantes.

A lógica do "tá tudo dominado" que guiava o ideal de ação dos traficantes no período pré- UPP perdeu um pouco de sua força dando lugar, sobretudo, à lógica do "tá tudo monitorado"» do contexto pós-"pacificação". Isso porque, após a UPPs, os traficantes entenderam que não podiam mais ter - e, em certo sentido, também não mais precisavam de - o domínio de todo o território da favela para continuar a venda de suas mercadorias. Contudo, eles tiveram, para isso, que transformar sua forma de vida para se adaptarem ao ambiente pós- UPPs. E, nessa nova lógica, o "bom traficante", isto é, a normatividade imanente do "traficante ideal" deixou de ser apenas pautada pela valorização do "ethos guerreiro" (Zaluar, 1996) e da disposição para o confronto ou para matar passando a ser também avaliado, em grande medi$\mathrm{da}$, por sua capacidade de manter-se "na atividade", ou seja, permanecer vigilante e sempre atento àquilo que está acontecendo ao seu redor. Ao dizer isso, não afirmo que esta segunda lógica não existisse antes ou o que a primeira tenha deixado de existir. Sustendo apenas que a dimensão da vigilância assumiu uma maior centralidade no modus operandi do tráfico no contexto pós- “pacificação”, dando relevo e

8. Estes dois bordões, “tá tudo dominado" e tá tudo monitorado”, fazem parte de letras de funks que fizeram muito sucesso. O primeiro funk, que "estourou” no início dos anos 2000, evidencia como a questão central para o tráfico era o domínio territorial da favela naquele momento. Enquanto o segundo funk, lançado em 2013, mostra que a questão do monitoramento passou a ser central, uma vez que a polícia e o tráfico passaram a conviver cotidianamente no mesmo território. 
intensificando essa capacidade de "estar em atividade" em detrimento daquela da "disposição para o confronto".

Vale notar que a lógica do monitoramento não tem a sua importância restrita ao tráfico, mas também à própria UPP. No início do processo de “pacificação”, os policiais também passaram a monitorar todos os "movimentos suspeitos" dentro das favelas. Isso tornou-se essencial para que a polícia, pouco a pouco, mapeasse "quem é quem" e descobrisse as formas de atuação dos traficantes locais; além disso, era necessária a intensificação do monitoramento para que os PMs pudessem escolher o melhor momento para "dar o bote" e capturar os “inimigos" em uma espécie de "jogo de gato e rato" (Menezes, 2015).

Com o jogo de "gato e rato" - uma expressão nativa, diga-se de passagem -, enfatizo o fato de que a lógica do confronto direto saiu de cena e assumiram o protagonismo as táticas de engano e a lógica das armadilhas. Pois o que estava em jogo nesse contexto do "gato e rato" da favela no início do processo de "pacificação" era menos a força bruta do confronto e mais a ação calculada que antecipa o erro de percepção e de atenção do outro. Era na boa dissimulação de seus próprios movimentos e na capacidade de fazer o outro ter uma percepção equivocada sobre a sequência de eventos que a lógica da captura se fundamentava. Daí porque a antecipação "do que o outro espera" (e "do que o outro espera que eu espere"; "do que o outro espera que eu espere do que ele espera" e assim ad inifinitum) se intensificava e uma espécie de hiperreflexividade calcada em antecipações emergiu. Uma nova configuração da reciprocidade de expectativas passou a fazer parte da fenomenologia do habitar dos territórios pacificados.

Com isso, uma considerável acentuação da tensão psicológica se estabeleceu. Ao tentar definir o que mudou com o processo de "pacificação", um traficante da Cidade de Deus afirmou que “agora a adrenalina tá na mente, cara!”. Mais importante do que o confronto armado e direto, seria, segundo este traficante, a estratégia mental, o raciocínio rápido e a capacidade de estar constantemente "na atividade". Outro jovem envolvido com o tráfico na Cidade de Deus, corroborando essa ideia, afirmou: "É, agora o negócio é mental [...] Se você não tiver na atividade, eles vão te pegar, porque eles já estão dentro [da favela], eles já estão infiltrados ali. Eles também conhecem o território e sabem por onde você pode circular. Então, não dá para relaxar, tem que estar sempre de olho aberto. É atividade o tempo todo!"

Em entrevista feita em 2013, esse mesmo jovem comparou as vantagens e as desvantagens de atuar como traficante antes e depois da UPP ${ }^{9}$. Em sua visão, após a

9. Outros traficantes também compararam, durante entrevistas, essas vantagens e desvantagens. Um deles me disse que: "como bandido, para mim não melhorou nada, só piorou de eu ganhar meu dinheiro. 
chegada da UPP, quem vendia droga havia deixado de ser definido como "bandido" e tinha se tornado sobretudo um "comerciante" ou "vendedor". A vantagem dessa mudança, segundo ele, consistiria no fato de que o risco de morrer passara a ser menor, ainda que, por outro lado, tenha tido como contrapartida um aumento de um outro tipo de "pressão psicológica". Em suas palavras:

Hoje é mais fácil ser bandido porque você tem a certeza de que é mais difícil você morrer, entendeu? Hoje não tem traficante, tem vendedores, tem comerciantes de drogas. Naquela época tinha BANDIDO. Hoje eles só vendem, não tem aquela pressão do polícia vir, você ter que meter a mão, dar tiro e arriscar a tua vida. Aquela adrenalina acabou [...]. Naquela época você aprendia a mexer no fuzil, mas também você podia morrer com muito mais facilidade. Hoje não. Hoje a polícia está dentro, você tem que monitorar. Tem menos confronto, mas também a pressão psicológica é maior, a atividade é outra e, em certo sentido, mais forte, mais intensa (Trecho de entrevista com jovem da Cidade de Deus).

A rotinização da upp, o (re) fortalecimento do tráfico e a (re) formatação dos "arregos"

Se no momento da inauguração das primeiras UPPs, ninguém sabia ao certo como o projeto seria desenvolvido e que resultados poderia gerar, passados os primeiros dois anos de "pacificação", o projeto conseguiu criar um "consenso" em torno de seus êxitos. Com a redução da letalidade, apoio dos moradores das favelas e do asfalto, notícias midiáticas que ventilavam as benesses do projeto, amparo do empresariado com fornecimento de suporte financeiro, além dos apoios dos governos nos três planos (municipal, estadual e federal), o "milagre" das upps passou a ser amplamente celebrado. Naquele momento, os que ousavam criticar o projeto ou eram imediatamente reduzidos à condição de defensores dos traficantes ou eram tratados como, para dizer o mínimo, desarrazoados (Menezes e Corrêa, no prelo).

Nos primeiros anos da implementação do projeto, pouco (ou quase nada) era dito na grande mídia sobre a presença do tráfico nas primeiras favelas "pacificadas". Contudo é importante ressaltar que, embora o tráfico de drogas no Santa Marta e na Cidade de Deus tenha se enfraquecido nesses primeiros anos, em 2011 moradores apontavam indícios de que os traficantes começavam a se fortalecer novamente nessas favelas.

Agora, sei que as coisas melhoraram para os moradores com certeza. Hoje sei que para criar filho é bem melhor. Bem melhor, porque eu posso deixar meu filho brincando aqui e ir lá atrás na praça jogar bola, que eu sei que quando eu voltar ele vai estar aqui, entendeu?" 
Entre 2011 e 2012, circulavam rumores ${ }^{10}$ e apareciam relatos de que traficantes estariam voltando a andar armados pelas favelas com UPP - sobretudo nos bailes. No caso do Santa Marta, ninguém nunca afirmou ter visto, de fato, um traficante armado no morro naquele período, mas muitos moradores com quem conversei a respeito disseram já ter ouvido boatos de que "os meninos estariam andando de pistola”. Enquanto conversávamos sobre o tema, alguns moradores acionaram outro rumor, apontando que traficantes não estariam andando armados nem enfrentando a polícia (como já acontecia em outras favelas, como a Cidade de Deus), porque o “dono do morro", preso na penitenciária de Bangu, queria evitar problemas com a polícia na favela para não correr o risco de ser transferido para um presídio de segurança máxima em outro estado do país.

Um rumor parecido também circulou pela Cidade de Deus, onde pessoas diziam que em uma área da favela não tinha enfrentamento armado porque o tal "dono" que comandava a venda de drogas na região proibia os bandidos de trocarem tiro dentro do território sob sua jurisdição. Já em outra área, com outro dono, a ordem seria inversa, a saber, seria para que bandidos atirassem em policiais que estavam “causando problemas" para o tráfico.

Cada dono de morro tem sua doutrina. Tem uns que não gostam de esculachar. $\mathrm{O}$ amigo daqui não quer esculachar ninguém. O ritmo dele é botar dinheiro no bolso e ficar milionário. Ele não quer que mate ninguém na favela porque ele também quer sair da cadeia e ficar em liberdade. Porque matando vagabundo na favela dele, acaba caindo nas costas dele e ficando mais difícil para ele sair depois. Dependendo da favela é diferente. Lá do outro lado, eles já mandam matar e jogam para o jacaré. Eles não querem saber não (Trecho de entrevista com um morador da Cidade de Deus).

Em 2012, contudo, surgiram relatos de que em todas as áreas da Cidade de Deus os "meninos" da boca de fumo estariam voltando a confrontar a polícia com o uso de armas de fogo. Um morador da Cidade de Deus afirmou que algumas "dinâmicas" que existiam no passado estariam voltando e a violência começava a "se naturalizar novamente".

Relatos apontavam, entre 2012 e 2013, ter havido um afrouxamento da regulação e da evitação do uso da força física nas favelas "pacificadas”. Moradores comentavam que se logo após a chegada da polícia os traficantes evitavam dar uma surra em alguém

10. Mapeei cerca de sessenta rumores que circularam pelo Santa Marta e pela Cidade de Deus desde a chegada da UPP e analisei essas narrativas como "notíciais improvisadas" que podem ser pensadas como “índices das preocupações” (Shibutani, 1966) dos moradores das favelas "pacificadas” (Menezes, 2014). 
que "vacilou”, para não atrair a atenção da polícia "pacificadora”, agora eles pareciam já não ter mais qualquer medo de empregar ações violentas - e isso até mesmo no caso do Santa Marta, considerada "favela-modelo".

Moradores da Cidade de Deus relataram que casos de agressões cometidas por traficantes também passaram a ocorrer com mais frequência a partir de 2013. E, além do crescimento dos casos de agressão, rumores começaram a apontar que os assassinatos e desaparecimentos estavam aumentando. Segundo um morador da Cidade de Deus, em uma conversa no aludido ano:

Morre gente toda semana na Cidade de Deus e você procura na estatística, no boletim de ocorrência, não tem. [...] A UPP não está aqui para proteger a gente, não. Eles estão aqui para proteger o território [...]. Tem policial que se preocupa com festa, se preocupa com coisas banais, que são coisas que já são do nosso cotidiano. E, ao mesmo tempo, eles fazem corpo mole e não correm atrás do que deveriam correr! (Trecho de entrevista com um morador da Cidade de Deus).

Como a fala dos moradores evidenciava em 2013, parecia estar tornando-se mais intensa a percepção, entre a população das áreas "pacificadas", de que, naquele momento, os policiais da UPP estavam fazendo "corpo mole" e não estavam se empenhando para evitar que ocorressem crimes nas favelas. É interessante notar que, por um lado, os policiais da UPP associavam o aumento da venda de drogas e a volta do fortalecimento do tráfico a um processo de "adaptação" dos traficantes ao novo contexto pós-"pacificação"; por outro, muitos moradores associavam o fato de o tráfico estar ganhando força com um outro processo que estaria simultaneamente ocorrendo nas favelas com UPP: a volta da corrupção.

Vale lembrar que no início da UPP o discurso oficial apontava que a maior parte do efetivo que atuaria em áreas "pacificadas" seria composta por policiais recém-formados. A utilização de policiais novatos, como indicam Siqueira e Rodrigues (2012), além de decorrer da necessidade de efetivo suficiente para as unidades, estava "associada à expectativa de que os novos policiais não compartilhassem dos mesmos 'vícios' daqueles que já praticavam as formas tradicionais de policiamento no Rio de Janeiro" (2012, p.11). Havia uma aposta de que a utilização de policiais recém-formados no projeto poderia ajudar a combater a corrupção dentro da UPP. $\mathrm{E}$, inicialmente, não apenas bradava-se nos principais meios de comunicação carioca como os próprios moradores tinham a percepção de que a UPP tinha conseguido gerar um "maior controle social, interno e externo, sobre a corrupção e o abuso de poder praticados por policiais” nos territórios 'pacificados” (Musumeci et al., 2013, p. 1).

No caso do Santa Marta, quando a major Priscilla Azevedo, a primeira comandante de uma favela "pacificada”, deixou o comando da UPP começaram a circular 
rumores de que os policiais estariam pedindo propina para "afrouxar" o policiamento do morro. Entre o final de 2010 e o início de 2011, quando um novo capitão assumiu a primeira UPP da cidade, muitos moradores começaram a notar que os policiais já não faziam mais rondas pelos becos e que só ficavam sentados dentro das viaturas ou parados em pontos fixos. Como apontou um morador da favela de Botafogo: "se os caras estão voltando a mostrar arma, isso porque o policial da UPP dá motivo [...]. O cara vai vender escondido, não vai botar fuzil, não vai botar pistola. Mas se não tiver, se tiver a possibilidade de mostrar a arma, a droga, ele vai mostrar".

$\mathrm{Na}$ Cidade de Deus, os moradores narravam sua percepção de que o policiamento fora "afrouxando" depois de mais ou menos dois anos que a ocupação da favela teve início. Meus interlocutores associavam tal "afrouxamento" a diversas modalidades de negociações financeiras entre policiais e traficantes que, pouco a pouco, começaram a ocorrer em áreas "pacificadas". Alguns desses arranjos - que fazem parte do que Misse (2006) chama de mercados de proteção agenciados pelas forças policiais - envolveram: (a) PMs pedindo "gorjetas" para comerciantes e "produtores culturais" para permitirem a realização de festas na favela, de modo que, assim, não houvesse um encerramento da atividade no horário imposto pelo comando local ou mesmo fiscalização a respeito do que estaria ocorrendo durante esses eventos; (b) policiais "capturando" ou "sequestrando" meninos da boca e pedindo "resgate" para que não fossem levados para delegacia ${ }^{11}$; (c) policiais "forjando flagrantes" com frequência; (d) PMs "comprando X9" (dando drogas, por exemplo, para "viciados" darem pistas sobre funcionamento do tráfico) e "vendendo $\mathrm{x} 9$ " (pedindo dinheiro para traficantes para entregar quem passou informações sobre o tráfico para UPP); (e) arranjos de arrego por guarnição ou por turno e mesmo "arrego por rua"; (f) acerto de "arrego por cima".

De forma resumida, é possível afirmar que, passados os primeiros anos após a inauguração das UPPs, parece ter havido redefinições nas negociações de "mercadorias políticas" (Misse, 2007) em áreas "pacificadas". Se antes traficantes de uma certa favela conseguiam pagar para ter o "alvará de funcionamento" (Barbosa, 2012) de todas as bocas de fumo de uma favela e, consequentemente, ter a liberdade de atuar por todo o território "arregrado" por um certo período de tempo (por uma semana por exemplo), passados os primeiros anos de "pacificação”, essas negociações pareciam acontecer muito mais no varejo (dependendo do plantão) e serem mais circunscritas espaço-temporalmente, isto é, relativas a uma porção muito bem deli-

11. Segundo um jovem que entrevistei: "quando pega com uma coisa assim, dependendo de quem for, se já rodou alguma vez, se está devendo eles, se tiver devendo, eles levam, se não estiver devendo... Por exemplo, me pegou, não sou pichado e ele me pegou, vai ser a primeira vez que eles vão me pegar. Aí eles pedem um dinheiro, $\mathrm{R} \$ 1.000,00, \mathrm{R} \$ 2.000,00$, vai um dinheiro para as mãos deles, eles me soltam”. 
mitada dentro do território, como uma rua específica, e a um determinado período bem delimitado de horas.

Durante uma entrevista realizada no inicio de 2016, um PM apontou que as negociações de "arrego" além de acontecerem "por baixo" (negociados diretamente com os "praças" de cada turno), mais recentemente também voltaram a acontecer, como antes da UPP, "por cima” (negociados com "oficiais"). Embora custasse mais caro, o "fechamento por cima" seria mais vantajoso porque o comandante ofereceria uma estrutura de trabalho melhor para os traficantes. Isso porque, tendo autonomia para "congelar" todas as viaturas da favela, o comandante não permitira que policiais circulassem e atuassem em nenhuma área de determinado território "pacificado". Como explicou um policial em uma entrevista:

\footnotetext{
Quando fecha com a guarnição, ela continua a circular e, se ver alguma coisa, finge que não viu. [...] Mas às vezes fecha por cima também [...] e você policial que está ali trabalhando em um certo turno não ganha nada. Aí o cara [comandante] pega você. [...] deixa parada em um ponto da favela, sem poder sair do lugar para patrulhar nada. Ele pega e fala "[...] fica aqui ó! Se você sair daqui, é punição". [...] Obviamente, o valor pago por cima é muito mais alto. Lá é comando. O cara vai te dar uma estrutura toda para você trabalhar, porque o cara vai congelar a tropa toda (Trecho de entrevista com um policial de UPP).
}

\section{A "crise" das upps}

Em novembro de 2010, o projeto de "pacificação" chega à Vila Cruzeiro e ao complexo do Alemão. A cena dos bandidos da Vila Cruzeiro fugindo para o Alemão circula o mundo todo e marca presença em todos os principais telejornais brasileiros. Trata-se de um "ponto de bifurcação” (Abbott, 2001) do processo pacificador. Como o próprio Beltrame afirmou posteriormente: esse evento foi "um divisor de águas na história da segurança pública do estado”. Exatamente no mesmo lugar em que, em 2002, o tráfico torturara e assassinara o jornalista da Rede Globo, Tim Lopes, a polícia agora ali triunfava. Anunciava-se que era a vitória definitiva da paz sobre a guerra; a vitória das forças do Estado sobre o arbítrio de narcotraficantes. Nas palavras de Beltrame: "a vitória do Alemão foi retumbante" e "provou-se que o Estado era quem mandava no território" (Beltrame, 2014, p. 145).

Paradoxalmente, o apogeu do projeto significou também o início da fase decrescente do consenso que se estabeleceu em torno das UPPs. Pois não foi senão a partir da ocupação das favelas maiores e mais complexas que alguns dos antigos problemas que, ao menos nas favelas pacificadas, pareciam ter sido definitivamente banidos, tais como os tiroteios e as mortes violentas, foram pouco a pouco voltando à cena. 
Nessas localidades, a polícia encontrou muito mais dificuldade para promover a chamada "pacificação" e isso, de certo modo, abalou a imagem do projeto como um todo (Menezes e Corrêa, no prelo).

A percepção de que o projeto estava "começando a desandar" intensificou-se, principalmente, a partir de 2012, quando foram inauguradas as UPPs da Rocinha e das favelas do Complexo do Alemão e da Penha. A expansão acelerada das UPPs para essas favelas maiores gerou preocupação não só nos moradores de áreas já "pacificadas", mas também nos policiais que passaram a se queixar alegando que o efetivo das UPPs mais antigas passou a ser progressivamente reduzido e deslocado para essas favelas maiores e que apresentavam mais problemas e resistência. As UPPS mais antigas passaram a ter que ceder, com frequência, policiais do seu efetivo para dar apoio e reforçar unidades mais recentes. Com o efetivo reduzido, já não era mais possível patrulhar adequadamente todo o território das favelas "pacificadas". Logo, os traficantes já não sentiam a necessidade de se esconder como no início da UPP e estariam se sedentarizando novamente, isto é, estabelecendo novamente bocas de fumo em lugares fixos.

Além da volta das “bocas sedentárias”, os conflitos armados e as mortes violentas também passaram a ocorrer com muito mais frequência em áreas com UPP. Como sintetizou um morador da Cidade de Deus: "eles começam a pegar confiança de pensar 'olha, já demos coro em um, já matamos outro e nada aconteceu'. [...] Então, aos poucos, parece que tudo vai voltando a ser como antes!".

Essa sensação intensificou-se ainda mais em 2013, depois do caso do desaparecimento de Amarildo na Rocinha ${ }^{12}$. O questionamento “Cadê o Amarildo?” virou uma das principais bandeiras das manifestações que tomaram conta das ruas da cidade do Rio de Janeiro e de quase todas as capitais brasileiras em junho e julho de 2013. Esse caso acabou abrindo espaço para um amplo questionamento das UPPs, quebrando o consenso que parecia existir em torno do projeto. Consenso esse que, por um longo período, deixou as UpPs blindadas às críticas, que nos últimos anos passaram a se proliferar, colocando assim a "estabilidade" do projeto em xeque.

Em 2014, os moradores da Cidade de Deus relataram que "tudo ficou tão complicado, os tiroteios se tornaram tão frequentes que a UPP passou a precisar de reforço" e, assim, voltaram a ocorrer operações policiais na favela. A realização dessas operações efetivadas pela polícia civil e/ou militar, com apoio do Core, do Bope e até de helicópteros da PM, passou a gerar um sentimento ambíguo. Por um lado,

12. Amarildo de Souza era morador da Rocinha e desapareceu depois de ser levado por policiais da UPP para prestar depoimento em julho de 2013. Apesar do corpo de Amarildo não ter sido encontrado, investigações apontam que ele foi torturado e assassinado por policiais. 
alguns moradores sentiram-se satisfeitos por acharem que a volta das operações era um sinal de que os policiais estariam tentando reprimir o tráfico. Por outro, contudo, algumas pessoas ficavam desconfiadas, pois o fato das operações serem necessárias em áreas que estariam "pacificadas" era considerado um sinal de que a "polícia de proximidade" não estaria mais dando certo e de que tudo parecia estar voltando a operar segundo a antiga lógica de operações violentas intermitentes.

Alguns moradores de áreas "pacificadas” especulavam, inclusive, que a polícia poderia estar "apertando o cerco" com operações contra o tráfico em áreas UPP para facilitar que ocorressem invasões. No caso do Santa Marta, moradores temiam uma invasão de uma facção rival ao $\mathrm{CV}^{13}$, enquanto na Cidade de Deus moradores temiam que milicianos da Gardênia Azul invadissem a favela.

Embora essas especulações de ameaças de invasão fossem diferentes no caso da Cidade de Deus e do Santa Marta, em ambos havia em comum uma desconfiança generalizada de todos contra todos, já que não era possível saber quais policiais estariam agindo dentro da lei e quais estariam "fechados" - isto é, colaborando - com o tráfico local ou, ainda, quais poderiam estar ajudando uma facção rival ou grupos de milicianos. Por isso, os moradores dessas favelas sentiam-se pressionados por todos os lados e, embora tivessem que conviver com arbitrariedades cometidas tanto por policiais como por traficantes ${ }^{14}$, sentiam-se receosos em fazer denúncias - seja contra o tráfico, seja contra a polícia -, uma vez que temiam por represálias em um cenário no qual o próprio domínio territorial parecia novamente estar em jogo, ou melhor, em forte disputa.

Em resumo, é possível dizer que, especialmente após as Olimpíadas de 2016, intensificou-se ainda mais a descrença em relação ao projeto das UPPs ${ }^{15}$, generalizada entre moradores, traficantes e até mesmo policiais. Esses últimos não parecem nem se lembrar mais que, nos primeiros anos de instalação das UPPs, existiu uma aposta de que estas poderiam ajudar a "pacificar", por um lado, a própria polícia ${ }^{16}$ - criando

13. No fim de 2014, circulou pelo Santa Marta um rumor de que a favela poderia ser invadida por traficantes da ADA (Amigos dos Amigos) depois que surgiram relatos de que o Morro Tabajaras teria sido invadido pela ADA, com apoio da UPP. Como o "dono" do tráfico no Santa Marta também seria o "dono" do Tabajaras, muitas pessoas começaram a especular que a favela de Botafogo poderia ser o próximo alvo da facção rival, o que gerou um forte clima de tensão.

14. Muitos moradores têm reclamado, por exemplo, que as lajes de suas casas na favela têm sido sistematicamente invadidas tanto pela polícia quanto pelo tráfico para servirem como bases militares.

15. Além disso, a incredulidade também atinge o governo do Estado como um todo: é sabido por todos que, nesse momento, ele passa por gravíssima crise econômica - isso para não falar nos escândalos de corrupção que levaram o ex-governador, Sérgio Cabral, à prisão.

16. Em 2012, Burgos et al. relataram que os moradores entrevistados pareciam ter a esperança de que a UPP promovesse uma "pacificação" da própria polícia. Eles acreditavam que a "nova polícia” poderia contaminar a "velha polícia". Como apontavam os autores: a questão central que estava em jogo na 
condições para permitir uma reforma mais ampla na corporação - e, por outro, o comércio varejista de drogas - modernizando a economia do tráfico ${ }^{17}$. Tais expectativas, contudo, frustraram-se quase por completo. Ao invés da "nova polícia” contaminar a "velha polícia", como se apostava inicialmente, exatamente o contrário parece ter ocorrido. No que diz respeito aos traficantes varejistas, muito embora em um primeiro momento eles parecessem estar se "modernizando" - isto é, parando de utilizar a lógica da força armada, transformando-se apenas em um comércio racionalizado de bens ilegais - agora parecem estar voltando a pautar suas ações a partir da lógica do que Machado da Silva chamou de "sociabilidade violenta"18.

Nesse cenário, a lógica da "pacificação" parece cada vez mais dar lugar à lógica da guerra - tanto em razão de um tráfico mais armado e propenso ao confronto quanto de uma postura mais agressiva por parte da polícia ${ }^{19}$. E essa (re)intensificação da lógica da guerra tem resultado em um aumento significativo do volume de mortes violentas em favelas, que em 2017 já atinge patamares semelhantes - ou, a depender da favela, até superiores - àqueles do período pré-"pacificação”.

Tudo isso vem contribuindo para que moradores, assim como policiais, afirmem que “a UPP está acabando” ou até mesmo que “a pacificação já acabou”, indicando, dessa forma, o evidente e definitivo esgotamento da tentativa do projeto de produzir um "policiamento de proximidade" em favelas cariocas.

experiência da UPP era a de saber em que medida ela poderia criar "condições que venham permitir a universalização dessa nova polícia, pautada pelo respeito aos direitos dos moradores das favelas e periferias, de que a UPP parece ser um ensaio" (2012, p. 91).

17. Segundo Luiz Eduardo Soares “o modelo de organização e operação do tráfico de drogas no Rio sempre foi irracional e tenderia a tornar-se insustentável. É muito caro manter controle armado e ostensivo sobre territórios e populações, dividindo lucros com policiais. Exercer esse controle exige a organização de equipes numerosas, disciplinadas, hierarquizadas, dispostas a assumir riscos extremos. Os benefícios podem ser obtidos com muito menos gastos e riscos, quando se opera com estruturas leves, adotando-se vendas por delivery ou por agentes nômades, circulando em áreas selecionadas - como ocorre nas grandes cidades dos países centrais. As UPPs [...] ao sepultarem o antigo regime, induzem, paradoxalmente, a modernização da economia do tráfico. [...] Essa modernização, considerando-se a inviabilidade de extinguir o negócio das drogas, será benéfica, reduzindo as armas em circulação e a violência, além do despotismo a que são submetidas tantas comunidades” (2011, p. 2).

18. Machado da Silva define "sociabilidade violenta" como uma forma de vida singular na qual "a força física, com ou sem instrumentos e tecnologias que a potencializam, deixa de ser um meio de ação regulado por fins que se deseja atingir, para se transformar em um princípio de coordenação (um 'regime de ação') das práticas. [...] A violência se libera da regulação simbólica [...]. Ela se torna um fim em si mesma, inseparável de sua função instrumental como recurso para a ação". (2010, p. 286)

19. Esse reforço da lógica da guerra em áreas "pacificadas" tornou-se ainda mais evidente no fim de 2016, quando o governo anunciou um caveirão branco como a grande "novidade das UpPs" e lançou, poucos meses depois, um plano de "reformulação" do projeto que envolveu a instalação de 26 torres e cabines blindadas em locais escolhidos com base em um mapeamento feito com drones em favelas "pacificadas". Tal plano de "blindar" a polícia dentro da favela, obviamente, recebeu muitas críticas já que só evidencia a incapacidade do projeto "pacificador" de seguir o caminho de um "policiamento de proximidade". 


\section{Considerações finais}

Para concluir, gostaria de retomar o debate sobre a gestão diferencial dos ilegalismos em favelas cariocas, buscando sintetizar quais foram os principais impactos da inauguração das UPPs nesse campo de forças. Para tanto, primeiramente, julgo importante apresentar alguns comentários sobre o que Telles e Hirata (2010) chamam de "face política dos ilegalismos urbanos".

Para os autores, a gestão diferencial dos ilegalismos tem suas modalidades de operação e aciona dispositivos de poder diferenciados, conforme o grau de incriminação dessas atividades. Algumas dessas modalidades de operação são "os agenciamentos políticos que oscilam entre a transgressão consentida, os mercados de proteção e as práticas de extorsão, além da repressão e da exposição à morte pelo uso da violência extralegal por parte das forças da ordem" (Idem, p. 42). Além disso, Telles e Hirata ressaltam que as dimensões políticas dos ilegalismos circunscrevem campos de força que ganham diferentes configurações. E essas configurações estão sempre diretamente relacionadas com seus modos de territorialização. A hipótese com a qual os autores trabalham é de que, "em torno desses ilegalismos, se estruturam campos de força e jogos de poder que deslocam, fazem e refazem a demarcação entre a lei e o extralegal, entre a justiça e a força, entre acordos pactuados e a violência, entre a ordem e seu avesso" (Idem, ibidem).

Para que possamos compreender as redefinições na gestão diferencial dos ilegalismos que ocorreram em favelas cariocas após a inauguração das UPPs, considero fundamental, por um lado, mapearmos as modalidades de operação dessa gestão e, por outro, analisarmos como essas modalidades variaram temporal e espacialmente, configurando diferentes campos de forças nos diversos momentos pós-UPP e nos distintos territórios "pacificados"20.

Sugiro que podemos organizar as modalidades de operação da gestão dos ilegalismos em favelas cariocas com base em três dinâmicas bastante amplas que apontam para um contínuo processo de experimentação no qual policiais e jovens que atuam no comércio varejista de drogas ilegais testam e mensuram a sua força e aquela do lado inimigo. Essas dinâmicas incluem: (a) negociações, que muitas vezes envolvem a exploração de "mercadorias políticas" (Misse, 2006) - como propinas, chantagens, extorsões e redes de proteção; (b) demonstrações efetivas de potência e poder, que muitas vezes envolve confrontos armados; (c) por fim, o

20. É importante que essas variações sejam ressaltadas para evitarmos uniformizar temporal e espacialmente a experiência das UPPs, ignorando como os impactos do projeto variaram muitíssimo ao longo do tempo e também de uma favela para outra. 
uso de diversos dispositivos de vigilância para monitorar os fluxos de circulação pelo território das favelas.

As duas primeiras dinâmicas citadas acima vêm sendo amplamente debatidas por diversos autores (Barbosa, 1998; Misse, 2006; Machado da Silva, 2008; Telles e Hirata, 2010) que destacam inclusive como ambas estão intimamente relacionadas. Grillo (2013) ressalta, por exemplo, como a dinâmica do confronto serve muitas vezes para testar as assimetrias de força, inflacionando ou tornando desnecessário o pagamento de suborno/extorsão à polícia para a manutenção do funcionamento regular das "bocas de fumo". E destaca ainda que essa mesma lógica pode ser também aplicada ainda a crueldade dos portadores da "sociabilidade violenta" (Machado da Silva, 2008), que também usam a explicitação da força como "disposição" subjetiva.

A terceira dinâmica, no entanto, ainda foi pouco explorada pela literatura, embora seja central para compreender as transformações geradas pela inauguração das UPPs na gestão dos ilegalismos. Obviamente, o uso de dispositivos de vigilância em favelas não é uma novidade, mas, desde 2008, ele foi amplamente diversificado e intensificado. Isso porque, com a inauguração das Upps, moradores, policiais e traficantes passaram a ter que dividir o mesmo território 24 horas por dia, sete dias por semana. E, como em um primeiro momento as dinâmicas de "arrego" foram interrompidas e as demonstrações de força envolvendo confrontos armados precisaram ser evitadas tanto pela polícia como pelo tráfico, a dinâmica da vigilância acabou ganhando predominância nos territórios "pacificados".

Um jogo de múltiplos monitoramentos se impôs com força nunca antes experimentadas nos ambientes favelados pós-“pacificação”. De um lado, a polícia instalou câmeras de vigilâncias em várias favelas com UPP; policiais passaram a usar seus celulares para tirar fotos ou filmar pessoas e situações suspeitas; e, mais recentemente, até drones ${ }^{21}$ passaram a ser utilizados no monitoramento dos territórios "pacificados". De outro, o tráfico espalhou olheiros munidos de celulares ou radinhos por inúmeros pontos da favela, visando monitorar os fluxos de pessoas, objetos e informaçóes pelo território. Além disso, ambos atores passaram também a empreender um largo esforço para monitorar os moradores tentando impedi-los de colaborar com o lado inimigo.

A dinâmica da vigilância tornou-se, portanto, central na gestão dos ilegalismos e parte integrante da fenomenologia do habitar em favelas "pacificadas", uma vez que, nos primeiros anos após a inauguração da UPP, monitorar o território tornou-se essencial para garantir a continuidade do funcionamento das "bocas de fumo". Mas vale ressaltar que a dinâmica da vigilância foi importante não só no momento inicial

21. Disponível em https://oglobo.globo.com/rio/policia-militar-usa-drone-para-mapear-complexo-do-alemao-21376436, consultado em 7 out. 2017. 
da "pacificação", como permanece sendo uma peça-chave na gestão dos ilegalismos em diversas favelas, mesmo no momento em que as upps estão em crise. Como o projeto das UPPs não foi oficialmente encerrado pelo governo do Estado e nem se sabe se isso ocorrerá - uma vez que uma incerteza generalizada paira sobre o seu horizonte de expectativas -, policiais e traficantes continuam dividindo o mesmo território, em um clima muito tenso e pouco previsível.

Em setembro de 2017, quando ocorreram intensos tiroteios na Rocinha - após Rogério Avelino da Silva, o Rogério 157, ter rompido com o chefe do tráfico no morro, Antônio Francisco Bonfim Lopes, o Nem -, diversas reportagens divulgadas na chamada grande mídia fizeram referência às dinâmicas de vigilância e contra vigilância presentes na favela. No dia 19 de setembro, por exemplo, uma reportagem divulgada no jornal $O$ Globo apontou que:

[...] desde que assumiu o controle da favela, em 2013, Rogério ignora a existência da UPP no local. Sua quadrilha, inclusive, criou uma solução ousada para monitorar a movimentação dos policiais: instalou câmeras dentro de caixas de plástico pretas em diversos locais da Rocinha e do Vidigal. No último dia 24 de maio, sete dessas câmeras foram apreendidas por policiais - uma na Rocinha e outras seis no Vidigal, perto da base da UPP. Um inquérito foi aberto na $11^{\text {a }} \mathrm{DP}$ (Rocinha) para investigar o caso (Trecho da reportagem "De guarda-costas a chefão, Rogério 157 instalou câmeras para monitorar PMs na Rocinha”22).

Um dia depois, uma reportagem do RJTV dizia que traficantes ligados a Rogério 157 estavam "revistando moradores da Rocinha em busca de mensagens de celular que possam revelar quem delata o tráfico"23. Ainda corroborando o clima de suspeição e tensão, poucos dias depois, uma matéria divulgada no site G1 indicava que um helicóptero do Exército havia sobrevoado a Rocinha, em 26 de setembro, lançando papéis com informações do disque-denúncia, pedindo que os moradores denunciassem a localização de criminosos ligados aos confrontos que estavam acontecendo na favela. A reportagem dizia ainda que moradores relataram que "pessoas estavam pedindo para ninguém pegar o panfleto que estava sendo jogado do helicóptero"24.

Tais episódios ocorridos na Rocinha mostram como aqueles que habitam, trabalham e circulam em favelas com UpP têm vivido, nos últimos anos, entre o "fogo

22. Disponível em https://oglobo.globo.com/rio/de-guarda-costas-chefao-rogerio-157-instalou-cameras-para-monitorar-pms-na-rocinha-21840848\#ixzz4uxX7hhqP, consultado em 7 out. 2017.

23. Disponível em https://g1.globo.com/rio-de-janeiro/noticia/traficantes-revistam-moradores-da-rocinha-em-busca-de-delatores.ghtml, consultado em 7 out.2017.

24. Disponível em https://g1.globo.com/rio-de-janeiro/noticia/helicoptero-das-forcas-de-seguranca-lancam-panfletos-na-rocinha.ghtml, consultado em 7 out. 2017. 
cruzado" e o "campo minado", ou seja, entre a ansiedade gerada pelos confrontos armados e a preocupação com o monitoramento da vida cotidiana, em seus movimentos mais infinitesimais. Em minha tese de doutorado (Menezes, 2015) analiso a nova fenomenologia do habitar que se instaurou no ambiente "pós-pacificação" - que chamo de regime de "campo minado". Mostro como esse regime territorial tem como características centrais o aumento dos dispositivos de vigilância que intensificam consideravelmente a sensação dos diversos atores (como moradores, policiais e traficantes) que habitam, trabalham ou circulam em favelas "pacificadas" de que estão sendo constantemente monitorados.

A sensação de estar constantemente "pisando em ovos" ou vivendo em um "campo minado" indica uma característica da vida cotidiana no contexto pós- "pacificação": uma espécie de imperativo de realização constante de antecipações. Antecipações essas que estão associadas a um incremento da autovigilância e que diferentemente das brilhantes análises goffmanianas, não se reduzem ao risco de "perder a face" (Goffman, 1967), mas sim de perder a própria vida. Isso significa que, nesse contexto, todos precisam fazer cálculos constantemente, ter cuidado e antecipar os riscos envolvidos antes que um passo seja dado, pois um simples passo errado pode "quebrar um ovo" ou detonar uma bomba - ou seja, pode ter por corolário imediato uma situação crítica que pode acabar envolvendo um desfecho violento.

Porém, vale ressaltar que a experiência de "campo minado" não é vivida sempre da mesma forma. Ela varia dependendo: (a) da pessoa, (b) do lugar e (c) do momento em questão. Embora o jogo de vigilância e contra vigilância envolva diversos atores e dispositivos de modo genérico - uma espécie de panoptismo de simetria generalizada -, ele é concretamente marcado por fortes assimetrias e envolve configurações muito distintas ${ }^{25}$. Pois se é verdade que moradores, assim como policiais e traficantes, se monitoram e vigiam (valendo-se do acionamento de diferentes dispositivos), não se pode ignorar que esses atores possuem recursos (e força) desiguais a depender da situação em jogo. Logo, a experiência de "campo minado" vivida por um policial, obviamente, não é a mesma de um traficante ou de um morador. E mesmo internamente a cada um desses grupos há muitas variações. Traficantes, policiais e moradores não são coletivos estanques e homogêneos. Eles

25. A vigilância exercida pelo tráfico e pela polícia embora sejam igualmente presentes na vida cotidiana da favela, são qualitativamente distintas. Para um morador de favela, obviamente, ser vigiado por um policial não é a mesma coisa do que se sentir monitorado por um traficante dentro do território da favela. Embora ambos os atores sejam potencialmente violentos e pouco previsíveis e possam usar técnicas similares em alguns casos - como instalar câmeras nas favelas e revistar celulares de residentes para verificar que informações estão circulando e tentar evitar possíveis denúncias ou delações -, as relaçôes que esses estabelecem com moradores das favelas podem ser bastante distintas e logo o temor e medo que despertam também não é o mesmo. 
também são heterogêneos, inclusive no que diz respeito aos recursos de que dispõem. Por isso, a sensação de estar sendo constantemente monitorado pode variar muito dependendo da atividade que cada um exerce e da posição que cada um ocupa na hierarquia da polícia ou do tráfico. Mas, independente dessa variação, fato é que todos que habitam, trabalham ou circulam por favelas cariocas, em alguma medida, precisam se preocupar com as dinâmicas de monitoramento que ganharam ainda mais centralidade nesses territórios nos últimos anos.

Para encerrar, gostaria de destacar que monitorar, negociar e confrontar têm se mostrado cada vez mais como práticas complementares diretamente associadas à gestão dos ilegalismos em favelas cariocas. Embora em alguns momentos e em favelas específicas uma dessas três dinâmicas tenha sido (e talvez ainda seja) mais central do que outras - como descrevi ao longo deste artigo -, sustento que analisar essas três modalidades de operação (ressaltando seus intercruzamentos) é fundamental para compreender como a gestão dos ilegalismos se define e redefine, circunscrevendo campos de força que ganham configurações diversas e próprias a seus modos de territoralização.

\section{Referências bibliográficas}

Аввотт, Andrew. (2001), Time matters: on theory and method. Chicago, University of Chicago Press.

BARBOSA, Antonio Rafael. (1998), Um abraço para todos os amigos: algumas considerações sobre o tráfico de drogas no Rio de Janeiro. Niterói, EDUfF.

Barbosa, Antonio Rafael. (2012), “Considerações introdutórias sobre territorialidade e mercado na conformação das Unidades de Polícia Pacificadora no Rio de Janeiro”. Revista Brasileira de Segurança Pública, 6 (2): 256-265.

Bautès, Nicolas \& Gonçalves, Rafael Soares. (2011), “Sécuriser l'espace des pauvres/Improving Security in Poor Areas". Revue Justice Spatiale/Spatial Justice, Paris, 4: 1-20, dez.

Beltrame, José Mariano. (2014), Todo dia é segunda-feira. Rio de Janeiro, Sextante.

Boltanski, Luc. (1990), L'amour et la justice comme compétences: trois essais de sociologie de laction. Paris, Métailié.

Boltanski, Luc \& ThÉvenot, Laurent. (1991), De la justification: les économies de la grandeur. Paris, Gallimard.

Burgos, Marcelo; Pereira, Luiz Fernando Almeida; Cavalcanti, Mariana; Brum, Mario \& Amoroso, Mauro (2012), "O efeito Upp na percepção dos moradores das favelas". Desigualdade \& Diversidade, 11: 49-97.

Cano, Ignacio; Borges, Doriam \& Ribeiro, Eduardo. (2012), Os donos do morro: uma 
análise exploratória do impacto das Unidades de Policia Pacificadora no Rio de Janeiro. São Paulo, Forum Brasileiro de Segurança Pública.

CORrêA, Diogo Silva. (2015), Anjos de fuzil: uma etnografia da relação entre Igreja e tráfico na Cidade de Deus. Rio de Janeiro, tese de doutorado em sociologia, Universidade do Estado do Rio de Janeiro.

Cunha, Neiva Vieira da \& Mello, Marco Antonio da Silva. (2012), "A upp e o processo de urbanização na favela Santa Marta”. In: Mello, Marco Antonio da Silva et al. Favelas cariocas: ontem e hoje. Rio de Janeiro, Garamond.

Das, Veena \& Poole, Deborah. (2004), Anthropology in the margins of the State. New Delhi, Oxford University Press.

DeLanda, Manuel. (2010), “Extensive and intensive cartography”. In: DeLanda, Manuel. Deleuze: history and science. Nova York, Atropos, pp. 115-140.

Dewey, John. (1938), Logic: the theory of inquiry. New York, Henry Holt.

Douglas, Mary. (1976), Pureza e perigo. São Paulo, Perspectiva.

Foucault, Michel. (1987), Vigiar e punir: nascimento da prisão. Petrópolis, Vozes.

Gibson, James. (1979), The ecological approach to visual perception. Boston, Houghton Mifflin Company.

Goffman, Erving. (1967), Interaction Ritual. Garden City, NY, Anchor Books.

Grillo, Carolina Christoph. (2013), Coisas da vida no crime: tráfico e roubo em favelas cariocas. Rio de Janeiro, tese de doutorado. Instituto de Filosofia e Ciências Sociais da Universidade Federal do Rio de Janeiro.

Grillo, Carolina Christoph. (mimeo.), "Fronteiras Tácitas: confronto e acordo em favelas do Rio de Janeiro".

INGOLD, Tim. (2000), The perception of the environment: essays in livelihood, dwelling, and skill. Londres/Nova York, Routledge.

Leite, Márcia Pereira. (2014), “Entre a 'guerra’ e a 'paz': Unidades de Polícia Pacificadora e gestão dos territórios de favela no Rio de Janeiro". Dilemas, 7: 625-642.

Machado Da Silva, Luiz Antonio (org.). (2008), Vida sob cerco: violência e rotina nas favelas do Rio de Janeiro. Rio de Janeiro, Nova Fronteira.

Machado Da Silva, Luiz Antonio. (2010), “Violência urbana', segurança pública e favelas: o caso do Rio de Janeiro atual”. Caderno CRH, 23 (59): 283-300.

Machado Da Silva, Luiz Antonio. (2015), “A experiência das UPPs: uma tomada de posição”. Dilemas, 8: 7-24.

Menezes, Palloma. (2014), “Os rumores da 'pacificação': a chegada da Upp e as mudanças nos problemas públicos no Santa Marta e na Cidade de Deus”. Dilemas, 7: 665-683.

Menezes, Palloma. (2015), Entre o "fogo cruzado" e o "campo minado": uma etnografia do processo de "pacificação" de favelas cariocas. Rio de Janeiro, tese de doutorado em sociologia, Instituto de Estudos Sociais e Políticos da Universidade do Estado do Rio de Janeiro. 
Menezes, Palloma. (2016), “La 'pacification’ et ses rumeurs: les incidences des Unités de Police Pacificatrices sur les problèmes publics dans les favelas de Rio de Janeiro". Contextes, 28: 1-16. Menezes, Palloma \& CorrêA, Diogo (no prelo). "From disarmament to rearmamento: elements for a sociology of critique of Pacifying Police Unit". Vibrant.

Menezes et al. (2017), "A pobreza turística no mercado de pacificação: reflexões a partir da experiência da Favela Santa Marta”. Cadernos do CRH, 29: 571-586.

Misse, Michel. (2006), Crime e violência no Brasil contemporâneo: estudos de sociologia do crime $e$ da violência urbana. Rio de Janeiro, Lumen Juris.

Misse, Michel. (2007), "Mercados ilegais, redes de proteção e organização local do crime no Rio de Janeiro". Estudos Avançados, 21: 139-157.

Musumeci, Leonarda; Mourão, Barbara M.; Lemgruber, Julita \& Ramos, Silvia (2013), "Ser policial de upp: Aproximações e resistências". Boletim Segurança e Cidadania, 14: 1-28. Shibutani, Tamotsu. (1966), Improvised news, a sociological study of rumor. Indianapolis/Nova York, The Bobbs-Merrill Co Inc.

Siqueira, Raíza \& Rodrigues, André. (2012), "As unidades de Polícia Pacificadora e a segurança pública no Rio de Janeiro”. Comunicações do ISER, 67 (31): 9-45.

SoAres, Luiz Eduardo. (2011), "Além do bem e do mal na cidade sitiada”. O Estado de S. Paulo, caderno Aliás, 20 nov.

Thévenot, Laurent. (1990), “L'action qui convient”. Raisons Pratiques, 1: 39-69.

Telles, Vera. (2010), A cidade nas fronteiras do legal e ilegal. Belo Horizonte, Fino Traço.

Telles, Vera da Silva \& Hirata, Daniel Veloso. (2010), "Ilegalismos e jogos de poder em São Paulo". Tempo Social, 22 (2): 39-59.

Valladares, Lícia do Prado. (2005), A invenção da favela: do mito de origem a favela.com. Rio de Janeiro, FGV.

VIGH, Henrik. (2009), "Motion squared: a second look at the concept of social navigation". Anthropological Theory, 9: 419-438.

Zaluar, Alba. (1996), Condominio do diabo. Rio de Janeiro, Editora da UFrJ/Revan. 


\section{Resumo}

Monitorar, negociar e confrontar: as (re)definições na gestão dos ilegalismos em favelas "pacificadas"

O objetivo deste artigo é analisar as (re)definições que ocorreram na gestão diferencial dos ilegalismos em favelas cariocas a partir da inauguração das Unidades de Polícia Pacificadoras. Com base em uma pesquisa etnográfica realizada nas duas primeiras favelas "pacificadas", mapeio os impactos da UPP nas modalidades de presença, nos modos de ação e de interação entre policias e jovens que atuam no comércio varejista de drogas ilegais. Defendo a hipótese de que monitorar, negociar e confrontar são as principais modalidades da gestão dos ilegalismos em favelas cariocas. E sugiro que analisar as variações e combinações entre essas modalidades é fundamental para compreender os campos de forças presentes em favelas "pacificadas" e, consequentemente, analisar o processo de ascensão e queda das UpPs.

Palavras-chave: Ilegalismos; Favela; Pacificação; Tráfico de drogas; Polícia.

\section{Abstract}

Monitoring, negotiating and confronting: the (re)definition on the management of illegalities in "pacified" favelas

The purpose of this article is to analyze the (re) definitions that occurred in the differential management of illegalities in Rio de Janeiro favelas since the Pacifying Police Units were launched. Based on an ethnographic fieldword carried out in the first two "pacified" favelas, I mapped out the UPP's outcomes on the modalities of presence, modes of action, and interaction between police and youth engaged in the illegal drug trade. I defend the hypothesis that monitoring, negotiating and confronting are the main modalities for the management of illegalities in Rio de Janeiro favelas. And I suggest that analyzing variations and combinations of these modalities is fundamental to understand the force fields that are set in "pacified" favelas and, consequently, to analyze the process of rise and fall of the UPPs.

Keywords: Illegalism; Favela; Pacification; Drug trafficking; Police.

Texto recebido em 29/5/2017 e aprovado18/10/2017.

DOI: 10.11606/0103-2070.ts.2018.133202.

palloma VAlle MENEzes é doutora em sociologia pela Universidade do Estado do Rio de Janeiro (IESP/UERJ) e pela Vrije Universiteit Amsterdam, professora adjunta do Departamento de Ciências Sociais da Universidade Federal Fluminense (UFF) e pesquisadora do projeto temático da Fapesp intitulado "A gestão do conflito na produção da cidade contemporânea: a experiência paulista”, coordenado por Vera da Silva Telles.E-mail: pallomamenezes@gmail.com. 